\title{
ARTICLE
}

https://doi.org/10.1057/s41599-019-0265-2

\section{The behavioral model and game theory}

\author{
Gholamreza Askari', Madjid Eshaghi Gordji \& Choonkil Park ${ }^{2}$
}

\begin{abstract}
The rational choice theory is based on this idea that people rationally pursue goals for increasing their personal interests. Here, we present a new concept of rational choice as a hyper-rational choice in which the actor thinks about profit or loss of other actors in addition to his personal profit or loss and then will choose an action that is desirable to him. We implement the hyper-rational choice to generalize and expand the game theory. Results of this study will help to model the behavior of people considering environmental conditions, the type of behavioral interaction, valuation system of itself and others, and system of beliefs and internal values of societies. Hyper-rationality helps us understand how human decisionmakers behave in interactive decisions.
\end{abstract}

\footnotetext{
${ }^{1}$ Department of Mathematics, Semnan University, Semnan, Iran. ${ }^{2}$ Department of Mathematics, Hanyang University, Seoul, South Korea. Correspondence and requests for materials should be addressed to G.A. (email: g.askari@semnan.ac.ir) or to M.E.G. (email: meshaghi@semnan.ac.ir)
} 


\section{Introduction}

he rational choice theory is one of the theories that predicts humans' and societies' behaviors in the social sciences. The main hypothesis in the prediction of humans' behavior is that these have an almost rational and targeted trend. In this theory, society is a set of the people, which has rational action. Principles and fundamentals of the rational actor are the basis of all social sciences theories, which have been explained by some theorists such as Weber (1978), Boudon (1998), and Elster (1989). This theory has been also criticized by many theorists. The theory of rational choice is a component of countless models that enhance our understanding of social phenomena. It would be easy to list many classical and modern sociological works and economic works that owe their scientific value to the fact that they use model. The works of economists and sociologists such as Olson (1965), Oberschall (1973, 1994), Kuran (1995), and Hardin (1995), among others, come to mind, as well as historians such as Root (1994) or political scientists such as Rothstein (2001). As Coleman (1986) states, "Rational actions of individuals have a unique attractiveness as the basis for social theory." Becker states (1996) "The extension of the utility-maximizing approach to include endogenous preferences is remarkably useful in unifying a wide class of behavior, including habitual, social, and political behavior." There are many technical introductions to rational choice theory and the interested reader is referred to the copious literature (see, Simon, 1972; Loomes and Sugden, 1982; Tversky and Kahneman, 1986).

Harsanyi (1980) defines rational action in routine life as a behavior through which people choose the best accessible means to achieve a definite goal. The first and yet the main application of the rational choice theory beyond economics is to use it in politics (Udehn, 2002). Herbert Simon is most famous for what is known to economists as the theory of bounded rationality, bounded rationality is the idea that in decision-making, rationality of individuals is limited by the information they have, the cognitive limitations of their minds, and the finite amount of time they have to make a decision (Simon, 1955). The most important theories based on the rational choice theory is decision-making theory (Schlaifer and Raiffa, 1961; Abelson and Levi, 1985), Collective action theory (Olson, 1965) and game theory (Von Neumann and Morgenstern, 1953). The theory of rational choice is one of the most important components of many game theory models. Hence, the rationality of the players is one of the fundamental principles, which led to generalization and expansion of this theory.

A choice of behavior in a single person decision-making problem is called player's action. The set of actions available is shown with $A$. Function $u: A \rightarrow \mathbb{R}$ which relates a outcome such as $u(a)$ with numerical to every member $a$ in $A$ is called payoff function. An individual's desires lead to a ranking of value outcomes in terms of preference (Webb, 2007). If a person prefers outcome $a_{1}$ to outcome $a_{2}$, we will show it as $a_{1}>a_{2}$. If a person is indifferent between the two outcomes $a_{1}$ and $a_{2}$, it will be shown as $a_{1} \sim a_{2}$. Showing $a_{1} \geqslant a_{2}$ means that person either prefers outcome $a_{1}$ to outcome $a_{2}$ or is indifferent between the two outcomes.

Definition 1(rationality) An individual will be called rational under certainty if their preferences for outcomes satisfy the following conditions:

1. (Completeness) Either $a_{1} \geqslant a_{2}$ or $a_{2} \geqslant a_{1}$.

2. (Transitivity) If $a_{1} \geqslant a_{2}$ and $a_{2} \geqslant a_{3}$ then $a_{1} \geqslant a_{3}$.

The completeness condition ensures that all outcomes can be compared with each other. The transitivity condition implies that outcomes can be listed in order of preference (Webb, 2007). One of the important problems of the rational choice theory is that it does not describe the rational behavior of human subjects as well. In the previous methods, failure to pay attention to outcome obtained for other decision-makers is the main negligence, which can have a considerable effect on the interactive decisions. Recently Eshaghi and Askari (2018) introduced a new concept of rational choice called hyper-rational choice. This study demonstrates that how human decision-makers behave in interactive decisions.

In this paper, in addition to the individual profit (individual preferences), which has been mentioned in the rational choice theory, we focused on profit or loss of other players, which led to the division of persons' preferences into two classes. The first class is the individual preferences to maximize his benefit or minimize his loss and the second class is preferences of the individual to maximize profit or loss of others (The person's preferences for others). The individual's choice among his preferences: individual preferences, preference for others and both of them at the same time, makes his hyper-preferences. Based on the idea, in most conditions, the hyper-rationality behavior of an actor is dependent on the person and others' behavior. Therefore, we present the unified approaches to analysis and cognition of humans and societies' behavior in social sciences. We implement the hyper-rational choice for interpretation strategic interaction between players. For this purpose, we will examine Prisoner's Dilemma.

The purpose of this paper is to describe a new concept of rationality for determining the importance of outcomes of other players in the game, which is designed to use in the game theory. The assumption of rational behavior is based on the fact that each player seeks the maximum benefit, but in assumption of hyperrational behavior, each player thinks about profit or loss of other actors in addition to his personal profit or loss and then will choose an action, which is desirable to him. One of the most important advantages of this concept emphasizes the importance of the outcomes of other actors in the game. Based on the concept of hyper-rationality, a player may not recognize that what action is the most beneficial to him but can choose an action, which causes the maximum loss or benefit for other players. With help of hyper-rational concept, we turn a rational individual into a hyper-rational individual. The aim is to explain the behavior of agents in a framework better and provide comprehensible understanding in human society. For this end, in the prisoner's dilemma game, various situations will be considered. Therefore, we achieve an equilibrium, which is not considered as game equilibrium based on the classical concept of rationality.

The outline of the paper is as follows: In section "Hyperrational Choice", we introduce a new concept of rationality as the hyper-rationality concept. In section "Hyper-rational Choice as the basis for game theory", we implement the hyper-rational choice as the basis for game theory to generalize and expand this theory. In section "Behavior of individuals in human societies", we model the behavior of players based on the hyper-rationality concept in human societies. We evaluate the proposed model with the prisoner's dilemma game. "Conclusion" section concludes.

\section{Hyper-rational choice}

Numerous results from experimental economics have shown that classic rationality assumptions do not describe the behavior of real human subjects. For example, it is not uncommon for people, in experimental situations, to indicate that they prefer $A$ to $B, B$ to $C$, and $C$ to $A$ (Alexander, 2002). If we consider profit or loss of other persons given rational behavior of the persons, which is based on individual benefit, some of the human behaviors may be 
described. In 1926 Ragnar Frisch developed for the first time a mathematical model of preferences in the context of economic demand and utility functions (Barten and Böhm 1982; Arrow et al., 1991). In 1944, Von Neumann and Morgenstern introduced the preferences as a formal relation (Von Neumann and Morgenstern, 1953).

Here, we divide preferences of people into two classes. The first class is a set of individual preferences (his or her profit, loss and indifferent between profit and loss) of the person, which seek to maximize his profit or minimize his loss. The second class is a set of preferences for others (profit for other, loss for other and indifferent between profit or loss for others) of the person, which seek to maximize profit or loss of other actors. Based on the second class of preferences (The person's preferences for others), assumption about profit or loss of other actors can be added in the form of human behaviors such as altruism, devotion, fraud, jealousy, and mistrust to the concept of rationality. As a result, the person has three choices about his preferences: individual preferences, preferences for other actors, and both of them simultaneously. Therefore, an individual's attitudes to other players' outcomes in a multi-player game lead to different type of ranking of preferences so-called hyper-preferences. Hence, the hyper-preferences for each individual specifies six behavioral options. Here, we consider four main behavioral options: individual profit, individual loss, profit for others, and loss for others. In the following, we want to turn a rational individual into a hyper-rational individual.

Now consider a rational individual. The set of possible choices of rational individual $i \in\{1,2, \ldots, n\}$ is shown with $A_{i}=\left\{a_{1}, a_{2}, \ldots\right.$, $\left.a_{n}\right\}$. Given hyper-preferences, how will a hyper-rational individual behave? We assume that given a set of choices $B \subseteq \mathcal{A}=A_{1} \times A_{2} \times \ldots \times A_{n}$. We define the weak hyperpreferences of actor $i$ ' over the set $B$ as follows:

$$
\begin{gathered}
\left(a_{1}, a_{2}, \ldots, a_{n}\right)_{i} \\
\succcurlyeq^{\prime}\left(b_{1}, b_{2}, \ldots, b_{n}\right)_{i} \Leftrightarrow \text { either } a_{1} \succcurlyeq b_{1} \text { or } a_{1}
\end{gathered}
$$

$\leqslant b_{1}$ based on actor $i^{\prime}$ preferences for actor 1 and either $a_{2} \succcurlyeq b_{2}$ or $a_{2}$

$\leqslant b_{2}$ based on actor $i^{\prime}$ preferences for actor 2 and either $a_{i} \succcurlyeq b_{i}$ or $a_{i}$

$$
\leqslant b_{i} \text { based on actor } i^{\prime} \text { preferences and either } a_{n} \succcurlyeq b_{n} \text { or } a_{n}
$$

$\leqslant b_{n}$ based on actor $i^{\prime}$ preferences for actor $\mathrm{n}$

where relation $\geqslant$ is complete and transitive and $\left(a_{1}, a_{2}, \ldots, a_{n}\right)$, $\left(b_{1}, b_{2}, \ldots, b_{n}\right) \in B$. We say that $\left(a_{1}, a_{2}, \ldots, a_{n}\right)$ is strictly preferred to $\left(b_{1}, b_{2}, \ldots b_{n}\right)$, or $\left(a_{1}, a_{2}, \ldots, a_{n}\right)>^{\prime}\left(b_{1}, b_{2}, \ldots, b_{n}\right)$, if $\left(a_{1}, a_{2}, \ldots, a_{n}\right) \geqslant b^{\prime}\left(b_{1}\right.$, $\left.b_{2}, \ldots, b_{n}\right)$ but not $\left(b_{1}, b_{2}, \ldots, b_{n}\right) \geqslant\left(a_{1}, a_{2}, \ldots, a_{n}\right)$. We say the actor is indifferent between $\left(a_{1}, a_{2}, \ldots, a_{n}\right)$ and $\left(b_{1}, b_{2}, \ldots, b_{n}\right)$, or $\left(a_{1}, a_{2}, \ldots\right.$, $\left.a_{n}\right) \sim^{\prime}\left(b_{1}, b_{2}, \ldots, b_{n}\right)$, if $\left(a_{1}, a_{2}, \ldots, a_{n}\right) \geqslant\left(b_{1}, b_{2}, \ldots, b_{n}\right)$ and $\left(b_{1}, b_{2}, \ldots\right.$, $\left.b_{n}\right) \geqslant\left(a_{1}, a_{2}, \ldots, a_{n}\right)$. So, we defined set of hyper-preference over set of preferences.

Definition 2. The relation $\geqslant$ 'on $B$ is complete if for all $\left(a_{1}, a_{2}\right.$, $\left.\ldots, a_{n}\right),\left(b_{1}, b_{2}, \ldots, b_{n}\right) \in B$ either $\left(a_{1}, a_{2}, \ldots, a_{n}\right) \geqslant\left(b_{1}, b_{2}, \ldots, b_{n}\right)$ or $\left(b_{1}\right.$, $\left.b_{2}, \ldots, b_{n}\right) \geqslant\left(a_{1}, a_{2}, \ldots, a_{n}\right)$, or both.

The completeness condition ensures that all action profiles can be compared with each other. Hyper-preferences help the person to consider more realistic conditions for decision-making and specify his objectives. Hyper-preferences of an individual have taxonomy characteristic. Taxonomy of hyper-preference means that if we face an actor with two choices of hyper-preferences, she will necessarily have an opinion on which she likes more. Taxonomy of actor's hyper-preferences depends on environmental condition, the type of behavioral interaction, beliefs system of itself and others and valuation system of itself and others. Taxonomy of hyper-preferences helps to a person to retrieve his/her preferences and reduces the rate of computation. Let $B \subseteq \mathcal{A}=$ $A_{1} \times A_{2} \times \ldots \times A_{n}$ be a nonempty set and $\geqslant$ is a relation on $B$.
Based on definition of the weak hyper-preferences of actor $i$, for all $\left(a_{1}, a_{2}, \ldots, a_{n}\right),\left(b_{1}, b_{2}, \ldots, b_{\mathrm{n}}\right)$ and $\left(c_{1}, c_{2}, \ldots, c_{n}\right)$ in $B$ we have:

1. (reflexivity) $\left(a_{1}, a_{2}, \ldots, a_{n}\right) \geqslant\left(a_{1}, a_{2}, \ldots, a_{\mathrm{n}}\right)$,

2. (antisymmetry) if $\left(a_{1}, a_{2}, \ldots, a_{n}\right) \geqslant\left(b_{1}, b_{2}, \ldots, b_{\mathrm{n}}\right)$ and $\left(b_{1}, b_{2}, \ldots\right.$, $\left.b_{n}\right) \geqslant\left(a_{1}, a_{2}, \ldots, a_{\mathrm{n}}\right)$ then $\left(a_{1}, a_{2}, \ldots, a_{\mathrm{n}}\right)=\left(b_{1}, b_{2}, \ldots, b_{\mathrm{n}}\right)$.

Depending on the person's hyper-preferences on the component of an action profile, transitivity property may exist or may not exist. In other words, based on definition of the weak hyperpreferences of actor $i$ for other actors, if $\left(a_{1}, a_{2}, \ldots, a_{n}\right) \geqslant\left(b_{1}, b_{2}, \ldots\right.$, $\left.b_{\mathrm{n}}\right)$ and $\left(b_{1}, b_{2}, \ldots, b_{\mathrm{n}}\right) \geqslant\left(c_{1}, c_{2}, \ldots, c_{\mathrm{n}}\right)$ then it can not be concluded $\left(a_{1}, a_{2}, \ldots, a_{n}\right) \geqslant\left(c_{1}, c_{2}, \ldots, c_{\mathrm{n}}\right)$.

For example, because of the environmental condition, the type of behavioral interaction and valuation system of actor $i$ and 1 , actor $i$ prefer $a_{1}$ to $b_{1}$, to $c_{1}$, and $c_{1}$ to $a_{1}$ for actors 1 . That is, if an individual simultaneously considers two classes of preferences, transitivity property of outcomes may do not exist. In section "Prisoner's Dilemma", based on collective profit or collective loss, transitivity property hyper-preferences do not exist. Considering situations, which the individual faces, we define hyper-rationality as follows:

Definition 3. (Hyper-rational) An individual will be called hyper-rational under certainty if is a rational (see Definition 1) and their hyper-preferences (individual or for others) satisfy at least one of the following conditions:

1. The actor chooses from the set of available alternatives (actions) based on individual preferences;

2. The actor chooses from the set of available alternatives (actions) based on preferences for other actors.

It can be concluded that each hyper-rational actor is a rational actor, but each rational actor is not a hyper-rational actor. In this concept, we call a person hyper-rational if he considers profit or loss of others in his interaction with other people in society in addition to individual profit or loss. Based on the concept of hyper-rationality, an actor may not identify an action, which has the maximum benefit for him but may be able to choose an action, which has the maximum profit or loss for other actors. So, attention to the emphasis on the importance of the outcome of other actors in the game is among the advantage of this concept. Hyper-rationality doesnot simplify decision-making but specifies how to make a decision. Hyper-rational actor removes information cognitive and processing constraints based on the taxonomy of hyper-preferences. The hyper-rational actor makes a decision based on his hyper-preferences and chooses an action, which is based on his targets despite knowing no access to full information. The number of decision-making stages is different among persons considering prioritization of hyper-preferences; therefore, hyper-rational doesn't mean limited searching.

Some human behaviors can be expressed with help of hyperrationality concept. The emergence of behavior such as jealousy in a person is due to the fact that since the person cannot increase his benefit and is unhappy of that, he prefers not to give more benefit to others. Also, a benevolent player can choose an action based on his hyper-rationality, which will bring more benefits to others. In contrast to a rational player with a hyper-rational player, the hyper-rational player has more chance of winning. Therefore, the concept of hyper-rationality can give a new concept of rationality called hyper-rational choice theory. Based on the new concept of hyper-rational choice, some of the human behaviors can be modeled with help of game theory.

\section{Hyper-rational choice as the basis for game theory}

Game theory aims to help us understand situations in which decision-makers interact. Like other sciences, game theory 
consists of a collection of models. A model is an abstraction that we use to understand our observations and experiences (Osborne, 2004). In order to describe a game, the set of possible choices of rational individual $i \in\{1,2, \ldots, n\}$ is shown with $A_{i}=\left\{a_{1}, a_{2}, \ldots, a_{n}\right\}$. So, each individual player $i$ has a set of actions $A_{i}$ available to him and a particular element in the set of actions is denoted by $a_{i} \in A_{\mathrm{i}}$. A profile of actions for the players is given by

$$
(a)=\left(a_{1}, a_{2}, \ldots, a_{n}\right) \in \prod_{i=1}^{n} A_{i}
$$

or alternatively by separating the action of player $i$ from all other players, denoted by $-i$ :

$$
(a)=\left(a_{i}, a_{-i}\right) \in\left(A_{i}, A_{-i}\right) .
$$

Finally there are payoff functions for each player $i$ :

$$
\begin{gathered}
U_{i}: A_{1} \times A_{2} \times \ldots \times A_{n} \rightarrow \mathbb{R} \\
U_{i}(a)=U_{i}\left(a_{1}, a_{2}, \ldots, a_{n}\right)=b \in \mathbb{R} .
\end{gathered}
$$

The concept of "game" indicates interactions between players as well but it has not been clarified in the mathematical modeling. In other words, mathematical modeling is unable to express dependency of strategy choice of a player on the decision made by other players. In the mathematical modeling, the dependency of decision choice by players has been expressed only based on the individual benefit of the players and no discussion has been made about player's preferences of loss or profit of other players.

Now, we apply hyper-rational choice theory as a basis and main element of modeling in game theory. With help of hyperrationality, we analyze conditions of a strategic game. In the concept of hyper-rationality, the player thinks about profit or loss of other players in addition to his personal profit or loss and then will choose an action, which is desirable to him. In order to describe a game based on concept of hyper-rational choice, the payoff functions for each player $i$ is given by:

$$
\begin{gathered}
U_{i}^{j}: A_{1} \times A_{2} \times \ldots \times A_{n} \rightarrow \mathbb{R} \\
U_{i}^{j}\left(a_{1}, a_{2}, \ldots, a_{n}\right)=\left\{\begin{array}{l}
U_{i}\left(a_{1}, a_{2}, \ldots, a_{n}\right) \text { if } i=j \\
U_{j}\left(a_{1}, a_{2}, \ldots, a_{n}\right) \text { if } i \neq j,
\end{array}\right.
\end{gathered}
$$

where $U_{i}^{j}$ shows that if player $i$ considers profit (loss) of player $j$, he will choose an action from a set of available actions, which will benefit (lose) player $j$, for every $i, j \in\{1,2, \ldots, n\}$. In other words, based on player i' preferences for player $j$, he thinks about profit or loss of player $j$ in addition to his personal profit or loss and then will choose an action from a set of available actions, which is desirable to him. For more information, see the Prisoner's Dilemma in Table 1.

In the theory of the game, different methods are used for finding equilibrium with help of rationality concept and one of

\begin{tabular}{|c|c|c|}
\hline \multirow[t]{2}{*}{ Player 1} & \multicolumn{2}{|c|}{ Player 2} \\
\hline & $C$ & D \\
\hline C & 3,3 & 1,4 \\
\hline$D$ & 4,1 & 2,2 \\
\hline
\end{tabular}
these methods is the best response function (McCarty and Meirowitz, 2007; Bu et al., 2017). Based on the definition of the best response function, equilibrium is a point in which strategy chosen by each individual is the best response to the strategies chosen by other players and maximize personal profit (Harsanyi,
1986; Eshaghi and Askari, 2017; Xia et al., 2019; Huang et al., 2018a, 2018b).

Hyper-rationality in game theory helps the player choose successful strategies of the game in interactive conditions and reproduce them. The concept of hyper-rationality helps the game theory enter other fields of sciences with more logical power. We assume that each player in the game is hyper-rational (for example two-player strategic $2 \times 2$ games with perfect information). Thus, a hyper-rational player will renormalize her opinion based on the common knowledge that each player is hyperrational. Below, we show the best response functions based on hyper-preferences of players with $B, P$, and $L$. Precisely, we define the best response function $\mathrm{B}_{i}$ based on individual benefit by

$$
B_{i}\left(a_{-i}\right):=\left\{a_{i} \in A_{i}: u_{i}\left(a_{i}, a_{-i}\right) \geq u_{i}\left(a_{i}^{\prime}, a_{-i}\right) \text { for all } a_{i}^{\prime} \in A_{i}\right\}
$$

any action in $B_{i}\left(a_{-i}\right)$ is at least as good based on individual benefit for player $i$ as every other action of player $i$ when the other players' actions are given by $a_{-i}$. We call $B_{i}$ the best response function of player $i$ based on individual benefit. Precisely, we define the best response function $P_{i}$ based on profit for other players by

$P_{i}\left(a_{-i}\right):=\left\{a_{i} \in A_{i}: u_{-i}\left(a_{i}, a_{-i}\right) \geq u_{-i}\left(a_{i}^{\prime}, a_{-i}\right)\right.$ for all $\left.a_{i}^{\prime} \in A_{i}\right\}$,

any action in $P_{i}\left(a_{-i}\right)$ for player $i$ relative to every other action of player $i$ is at least the best based on profit for other players when the other players' actions are given by $a_{-i}$. We call $P_{i}$ the best response function of player $i$ based on profit for other players. Precisely, we define the best response function $L_{i}$ based on the loss of other players by

$L_{i}\left(a_{-i}\right):=\left\{a_{i} \in A_{i}: u_{-i}\left(a_{i}, a_{-i}\right) \leq u_{-i}\left(a_{i}^{\prime}, a_{-i}\right)\right.$ for all $\left.a_{i}^{\prime} \in A_{i}\right\}$,

any action in $L_{i}(a-i)$ for player $i$ relative to every other action of player $i$ is at least as good based on the loss for other players when the other players' actions are given by $a_{-i}$. We call $L_{i}$ the best response function of player $i$ based on the loss of other players. From relations (1), (2), and (3) we have,

$$
B_{i}\left(a_{-i}\right) \cup P_{i}\left(a_{-i}\right) \cup L_{i}\left(a_{-i}\right)=A_{i}
$$

In competitive interactions, we define strictly dominant action and weakly dominant action based on the loss of other players.

Definition 4. (Strict domination of loss) In a strategic game for player $i$, action $a_{i}$ " is strictly dominant on her action $a_{i}^{\prime}$ based on loss for player $-i$, if we have:

$$
u_{-i}\left(a_{i}^{\prime \prime}, a_{-i}\right)<u_{-i}\left(a_{i}^{\prime}, a_{-i}\right) \text { for every } a_{-i} \in A_{-i},
$$

where $u_{-i}$ is a payoff function that represents player $-i^{\prime}$ preferences. It is defined as strictly dominant action based on benefit for other players similar, but the difference is that direction of the relation $<$ is changed.

Definition 5. (Weak domination of loss) In a strategic game for player $i$, action $a_{i}{ }^{\prime \prime}$ is weakly dominant on her action $a_{i}{ }^{\prime}$ based on loss for player $-i$, if we have:

$$
u_{-i}\left(a_{i}^{\prime \prime}, a_{-i}\right) \leq u_{-i}\left(a_{i}^{\prime}, a_{-i}\right) \text { for every } a_{-i} \in A_{-i},
$$

and

$$
u_{-i}\left(a_{i}^{\prime \prime}, a_{-i}\right)<u_{-i}\left(a_{i}^{\prime}, a_{-i}\right) \text { for some } a_{-i} \in A_{-i},
$$

where $u_{-i}$ is a payoff function that represents player $-i^{\prime}$ preferences. It is defined as weakly dominant action based on benefit for other players similar, but the difference is that direction of relations $\leq$ and $<$ is changed. 
The actions, which are chosen based on the concept of hyperrationality (hyper-preferences) and rationality of the players, may be similar or different. According to the concept of hyper-rationality, we divide actions of players into three classes: (1) strictly dominant action and weakly dominant action based on individual profit; (2) strictly dominant action and weakly dominant action based on profit for other players; (3) strictly dominant action and weakly dominant action based on the loss for others. The following proposition shows a method for finding equilibrium in the game.

Proposition 6. The action profile $a^{*}$ is a equilibrium point of strategic game if and only if hold true in at least one of the following conditions:

- Each action of the player is the best response to actions of other players based on personal benefit:

$$
a^{*} \text { is in } B_{i}\left(a_{-i}^{*}\right) \text { for every player } i
$$

- Each action of the player is the best response to actions of other players based on the benefit of other players:

$$
a^{*} \text { is in } P_{i}\left(a_{-i}^{*}\right) \text { for every player } i
$$

- Each action of the player is the best response to actions of other players based on loss of other players:

$$
a^{*} \text { is in } L_{i}\left(a_{-i}^{*}\right) \text { for every player } i \text {. }
$$

We consider equilibrium based on concept of Nash (Nash, $1950,1951)$. Based on the concept of hyper-rationality, equilibria can be divided into three classes. The first class is the equilibria, which are considered based on personal benefit. The second class is the equilibria, which are selected based on profit or loss of other players. The third class is the equilibria, which are considered based on individual benefit and loss or profit of other players at the same time. An action profile may be selected, which is the equilibrium point of the game based on hyper-preference of the maximum loss for other players and also has the maximum loss for all players, but it is not Nash equilibrium based on the classic concept of rationality. In addition, based on this concept, games may have one (Second Best game), two (Prisoner's Dilemma), three (Trickery game) and four (Chicken game) equilibrium or without an equilibrium. For example, the Matching pennies is not in equilibrium and Missile crisis game has two equilibria. Hyperrationality helps the analyst to interpret every cell of the game table and have more accurate analysis.

\section{Behavior of individuals in human societies}

In a social dilemma game, there are different behavioral options, for cooperation and competition (Hertel and Fiedler, 1994; Huang et al., 2018a, 2018b; Li et al., 2018a, 2018b). There are several studies, which provide the main theoretical insights of the general psychological game framework (Geanakoplos et al., 1989; Attanasi and Rosemarie Nagel, 2008; Li et al., 2016). The classical theory of game relies on assumptions of perfect rationality and full common knowledge that are far removed from the cognitive capacities of human players and of limited use in explaining human strategic behavior. On the other hand, blind experimentation is also unhelpful, because the proper use of experiments is to test hypotheses, and without good hypotheses, no useful progress can be made (Colman and Pulford, 2015). Interactions between psychologists and economists have been marked more by conflict than by collaboration and the absence of a common research language impedes communication between this the disciplines (Manski, 2017). Some of the studies describe the relationship between psychologists and economists (Croson and Miller, 2004; Attanasi and Rosemarie Nagel, 2008; Schotter and Trevin, 2014; De Bruin and Fischhoff, 2017; Xia et al., 2018). In this section, we review and interpret Prisoner's Dilemma with the help of the concept of hyper-rationality.

Prisoner's Dilemma. The prisoner's dilemma (PD) game can be used as a model for many real world situations involving cooperative behavior. The players in PD have two options. They must either cooperate or defect. In the simultaneous PD all players make their decisions or moves at once. Mathematical models have further established the prisoner's dilemma as foundational lore in fields as diverse as economics, political science, environmental studies, psychology, and evolutionary biology. Advertising is sometimes cited as a real-example of the prisoner's dilemma (Moorthy, 1985). In environmental studies, the PD is evident in crises such as global climate-change (Osang and Nandy, 2013). Cooperative behavior of many animals can be modeled as iterated the prisoner's dilemma. Interest in the iterated prisoner's dilemma (IPD) was kindled by Robert Axelrod (1984) in his book The Evolution of Cooperation. The essence of cooperation is described by the Prisoner's Dilemma (Dreber et al., 2008). Cooperation is a hallmark of human society (Trivers, 1971; Hamilton and Axelrod, 1981; Rockenbach and Milinski, 2006; Nowak, 2006; Rand et al., 2009, 2011, 2012, 2014; Li and Daniels, 2015). In theory of games, there has been much interest in exploring the Prisoner's Dilemma.

Here, we claim that based on the hyper-rationality concept each player in the Prisoner's Dilemma is hyper-rational. In Table 1 based on definitions of hyper-rationality we have;

1. Each player is thinking of making a profit to another player. In game $G$, for player 1 we have: based on concept of hyperrationality, given fixed $C$ for player 2 , we can see that if player 1 , seeks to incur profit to his opponent, he will choose $C$ (player 2, earns a reward 4), it can conclude that pair of action $(C, C)$ is chosen. By choosing $D$ for player 2 , we can see that if player 1 , seeks to incur profit to his opponent, he will choose $C$ (player 2, earns a reward 4 ), it can conclude that pair of action $(C, D)$ is chosen. Therefore, for the player 1 , based on the profit of another player, $C$ is a strictly dominant action.

In game $G$, for player 2 we have: based on concept of hyperrationality, given fixed $C$ for player 1 , we can see that if player 2 , seeks to incur profit to his opponent, he will choose $C$ (player 1 , earns a reward 4), it can conclude that pair of action $(C, C)$ is chosen. By choosing $D$ for player 1 , we can see that if player 2, seeks to incur profit to his opponent, he will choose $C$ (player 1 , earns a reward 4), it can conclude that pair of action $(D, C)$ is chosen. So, for the player 2, based on the profit of another player, $C$ is a strictly dominant action.

2. Player 1 is looking to profit for player 2 and player 2 seeks to lose of player 1 . In game $G$, for player 1 we have: based on concept of hyper-rationality, given fixed $C$ for player 2 , we can see that if player 1 , seeks to incur profit to his opponent, he will choose $C$ (player 2, earns a reward 4), it can conclude that pair of action $(C$, $C$ ) is chosen. By choosing $D$ for player 2 , we can see that if player 1 , seeks to incur profit to his opponent, he will choose $C$ (player 2, earns a reward 4), it can conclude that pair of action $(C, D)$ is chosen. Therefore, for the player 1, based on the profit of another player, $C$ is a strictly dominant action.

In game $G$, for player 2 we have: based on concept of hyperrationality, given fixed $C$ for player 1 , we can see that if player 2 , seeks to incur loss to his opponent, he will choose $D$ (player 1 , earns a reward 1), it can conclude that pair of action $(C, D)$ is chosen. By choosing $D$ for player 1 , we can see that if player 2, seeks to incur loss to his opponent, he will choose $D$ (player 1 , earns a reward 2), it can conclude that pair of action $(D, D)$ is 
chosen. So, for players 2, based on the loss of another player, $D$ is a strictly dominant action.

3. Each player is thinking of making a loss to another player. In game $G$, for player 1 we have: based on concept of hyperrationality, given fixed $C$ for player 2 , we can see that if player 1 , seeks to incur loss to his opponent, he will choose $D$ (player 2, earns a reward 1), it can conclude that pair of action $(D, C)$ is chosen. By choosing $D$ for player 2, we can see that if player 1 , seeks to incur loss to his opponent, he will choose $D$ (player 2, earns a reward 2), it can conclude that pair of action $(D, D)$ is chosen. Therefore, for the player 1 , based on the loss of another player, $D$ is a strictly dominant action.

In game $G$, for player 2 we have: based on concept of hyperrationality, given fixed $C$ for player 1 , we can see that if player 2 , seeks to incur loss to his opponent, he will choose $D$ (player 1 , earns a reward 1), it can conclude that pair of action $(C, D)$ is chosen. By choosing $D$ for player 1 , we can see that if player 2 , seeks to incur loss to his opponent, he will choose $D$ (player 1 , earns a reward 2), it can conclude that pair of action $(D, D)$ is chosen. So, for players 2 , based on the loss of another player, $D$ is a strictly dominant action.

4. Player 1 is looking to loss to player 2 and player 2 seeks to profit for player 1 . In game $G$, for player 1 we have: based on concept of hyper-rationality, given fixed $C$ for player 2 , we can see that if player 1 , seeks to incur loss to his opponent, he will choose $D$ (player 2, earns a reward 1), it can conclude that pair of action $(D$, $C$ ) is chosen. By choosing $D$ for player 2, we can see that if player 1 , seeks to incur loss to his opponent, he will choose $D$ (player 2, earns a reward 2), it can conclude that pair of action $(D, D)$ is chosen. Therefore, for the player 1 , based on the loss of another player, $D$ is a strictly dominant action.

In game $G$, for player 2 we have: based on concept of hyperrationality, given fixed $C$ for player 1 , we can see that if player 2 , seeks to incur profit to his opponent, he will choose $C$ (player 1 , earns a reward 4), it can conclude that pair of action $(C, C)$ is chosen. By choosing $D$ for player 1 , we can see that if player 2 , seeks to incur profit to his opponent, he will choose $C$ (player 1 , earns a reward 4), it can conclude that pair of action $(D, C)$ is chosen. So, for the player 2, based on the profit of another player, $C$ is a strictly dominant action.

Therefore, in Prisoner's Dilemma $G$ for both players based on loss of other players, defect $D$ is a strictly dominant action of loss and cooperate $C$ is a strictly dominated action of loss. In this game, equilibrium point $(D, D)$ is an equilibrium, which the players selected based on loss of the opponent. For both players, based on the benefit of other players, cooperate is a strictly dominant action of profit and defect is a strictly dominated action for profit. So, equilibrium point $(C, C)$ is an equilibrium, which the players selected based on the benefit of the opponent. Therefore, based on the hyper-rationality concept, prisoner's dilemma has two equilibria $(C, C)$ and $(D, D)$. Hofstadter claims that for the super-rational it is evident that universal cooperation is the best option (Poston, 2012; Hofstadter, 2008). We state that either cooperation or defection is the best option for the hyperrational player depending on environmental conditions (competitive, peace, war,...) and the type of behavioral interaction (friend, enemy,...) in game. One can almost be claimed that the cooperation and the defection are two hyper-rational options. On the other hand, when players cannot guarantee their profit, they can optimize the situation by defection. As a result, cooperation is not always the best option.

Cooperation leads to a tension between what is best for the individual and what is best for the group (Dreber et al., 2008). How can the cooperation be promoted in the repeated prisoner's dilemma? In some experimental papers to promote cooperation from complicated laboratory conditions or add strategy to the Prisoner's Dilemma is used (Sigmund et al., 2008; Fehr and Gachter, 2002; Ohtsuki et al., 2009; Traulsen and Nowak, 2006; Mathew and Boyd, 2011; Gallo and Yan, 2015; Jordan et al., 2016; Bear and Rand, 2016; Li et al., 2018a, 2018b). We want to answer the above question using the concept of hyper-rationality. In classical game theory, all the variety of $2 \times 2$ symmetric games rests in the relative values of the four payoffs $(C, C),(D, D),(D, C)$, and $(C, D)$. There are 24 possible rankings of four payoffs, and thus 24 symmetric $2 \times 2$ games (Poundstone, 1993). In Prisoner's Dilemma based on classical rationality, row player prefers $(D, C)$ to $(C, C)$ to $(D, D)$ to $(C, D)((D, C) \geqslant(C, C) \geqslant(D, D) \geqslant(C, D))$. The hyper-rationality of player thinks about profit or loss of other players in addition to his personal profit or loss and then will choose an action, which is desirable to him. As mentioned above, taxonomy of player's hyper-preferences depends on environmental condition, the type of behavioral interaction, selfevaluation system and evaluation system of other interacting persons. Taxonomy of player's hyper-preferences has four main behavioral options: individual profit, individual loss, profit for others, and loss for others. Hence, in Prisoner's Dilemma row player take taxonomy of hyper-preferences considering four main behavioral options: based on individual profit: $(D, C) \geqslant(C, C) \geqslant$ ' $(D, D) \geqslant(C, D)$, based on individual loss: $(C, D) \geqslant(D, D) \geqslant{ }^{\prime}(C$, $C) \geqslant{ }^{\prime}(D, C)$, based on profit for others: $(C, D) \geqslant{ }^{\prime}(C, C) \geqslant(D, D) \geqslant$ ' $(D, C)$, based on loss for others: $(D, C) \geqslant{ }^{\prime}(D, D) \geqslant '(C, C) \geqslant{ }^{\prime}(C, D)$.

Hyper-preferences taxonomy helps that players consider simultaneously two main behavioral options such as collective profit or collective loss (Eshaghi Gordji et al. 2018). If interaction between players is based on collective benefit thinking, both player prefers: either $(C, C) \geqslant^{\prime}(D, D) \geqslant \prime(D, C) \geqslant \prime(C, D)$ or $(C, C) \geqslant$ ' $(D, D) \geqslant(C, D) \geqslant(D, C)$. On the other hand, the concept of hyper-rationality explains that, based on the profit of other players, cooperation is a strictly dominant action. Taxonomy of hyper-preferences helps to players consider two principles simultaneously in interactions: first, treat others as we ourselves would like to be treated and second, not treat others as we ourselves would not like to be treated. According to the second principle, the profiles strategy $(C, D)$ and $(D, C)$ is not selected. Based on collective benefit thinking $(C, C)$ is preferred to $(D, D)$ by two players. So, according to the first principle, the profiles strategy $(C, C)$ is selected. If the Prisoner's Dilemma is repeated, the taxonomy of two principles are likely to lead to this mechanism for the promotion of cooperation. Hence, this study with the help of the concept of hyper-rationality in game theory, seeks to the promotion of cooperation between the players, which is a sign of the power of this concept. Therefore, the concept of hyper-rationality helps to understand the evolution of cooperation.

There are two competing classes of theories that investigate the relationship between actions and beliefs. The first class of theories, coming from economics, suggests that beliefs cause actions. The second class of theories, proposed by psychologist, suggest that actions cause beliefs (Croson and Miller, 2004; Attanasi and Rosemarie Nagel, 2008). Interactions between psychologists and economists have been marked more by conflict than by collaboration (Manski, 2017). Bruine de Bruin and Fischhoff describe four conditions that promoted transdisciplinary collaborations between psychologists and economists (De Bruin and Fischhoff, 2017). We explore the players' behavior with the help of the concept of hyper-rationality. This concept explains that, based on the loss of other players, defection is a strictly dominant action. If interaction between players is based on collective loss thinking, both player prefers: either $(D, D) \geqslant(C, C) \geqslant \prime(D, C) \geqslant$ $(C, D)$, or $(D, D) \geqslant^{\prime}(C, C) \geqslant^{\prime}(C, D) \geqslant^{\prime}(D, C)$. These interpretations help to enlarge our understanding of psychological aspects of 
strategy choices in games and also provide an analysis of the decision-making process with cognitive economics approach at the same time. For example, based on collective thinking and two principles mentioned above if players have hostile thoughts that only cause loss to another player then they prefer $(D, D)$ to $(C, C)$. In other words, the hyper-preferences indicate that the type of behavioral interaction, environmental conditions, and valuation system are based on hostility and players at this point have considered the maximum loss to other, which this is a common research language between psychologists and economists.

Computational complexity. In general, the hyper-rationality concept can be used as a compatible model for many real world situations. The individual's choice among his preferences: (i) individual preferences, to maximize his benefit or minimize his loss; (ii) preference for others, to maximize profit or loss of other players, and (iii) both of them at the same time, makes his hyperpreferences. The computational complexity of our method depends on the number of players and actions and these three steps. In other words, the more the number of players and actions, the higher the computational complexity. Obviously, part (iii) is of the highest complexity, while the complexity of the other two parts is rather low. Our method is very easy to implement and suitable for a lot of large-scale real networks.

\section{Conclusion}

The theory of rational choice seeks to explain the behavior of the person who behaves wisely and look for to maximize his benefits. The theory of hyper-rational choice seeks to explain the behavior of the person who behaves wisely and considers benefit or loss of others in addition to the individual benefit. The theory of hyperrational choice can be applied instead of the theory of rational choice in social sciences and society can be analyzed based on two methodological individualistic and methodological collective approaches so that human society can be understood easily and predicted more fluently. In this theory, the hyper-rational actor thinks about the benefit (collective benefit) and loss (collective loss) of other actors beside his own benefit and then chooses an action. Based on this concept, we call a person hyper-rational if results of choosing any action are comparable with other actions for the person and also the person can recognize what action is the most beneficial to him among the accessible actions and what action causes loss or benefit of other players. According to the concept of hyper-rationality, a player may not recognize that what action is the most beneficial to him but can choose an action, which causes the maximum loss or benefit for other players. Based on this concept, assumption about profit or loss to other actors can be added in the form of human behaviors such as altruism, devotion, fraud, jealousy, and mistrust to the concept of rationality. This new concept can describe some of the human behaviors well.

Moreover, we presented new definitions such as the best response functions, strictly dominant action and weakly dominant action based on loss of other players. With the help of these definitions, we have introduced a method for finding equilibrium in the game and classified the equilibria. In some of these games, we achieved equilibria, which are not considered as game equilibrium based on the classic concept of rationality. The theory of hyper-rational choice can be applied as a basis for the theory of decision-making, the theory of collective action and social sciences issues and new results can be obtained in this way. Hyperrationality can be mentioned and investigated as uncertainty. We also believe that our current design has some additional advantages over previous ones. The hyper-preferences indicate that if the type of behavioral interaction, environmental conditions, and valuation system are based on hostility, then players have considered the maximum loss to other, which can be a common research language between psychologists and economists.

\section{Data availability}

Data sharing is not applicable to this paper as no datasets were analysed or generated.

Received: 23 January 2019 Accepted: 7 May 2019

Published online: 28 May 2019

\section{References}

Abelson RP, Levi A (1985) Decision making and decision theory. Handb Soc Psychol 1:231-309

Alexander JM (2002) Evolutionary Game Theory. En The Stanford Encyclopedia of Philosophy (Summer 2003 Edition). E. N. Zalta. Stanford University Stanford

Arrow KJ, Intriligator MD, Hildenbrand W, Sonnenschein H (1991) Handbook of mathematical economics. North-Holland, Amsterdam

Attanasi G, Rosemarie Nagel R (2008) A survey of psychological games: theoretical findings and experimental evidence. Games, Rationality and Behavior. In: Innocenti A and Sbriglia P (eds) Essays on behavioral game theory and experiments. Palgrave McMillan, Houndmills, pp. 204-232

Axelrod R (1984) The evolution of cooperation. Basic Books, Inc., New York, NY Barten AP, Böhm V (1982) Consumer theory. Handb Math Econ 2:381-429

Bear A, Rand DG (2016) Intuition, deliberation, and the evolution of cooperation. Proc Natl Acad Sci 113(4):936-941

Becker G (1996) Accounting for Tastes. Harvard Univ. Press, Cambridge, pp. 1996 Boudon R (1998) Limitations of rational choice theory. Am J Sociol 104 (3):817-828

Bu Z, Li HJ, Cao J, Wang Z, Gao G (2017) Dynamic cluster formation game for attributed graph clustering. IEEE Trans Cybern 49(99):1-14

Coleman J (1986) Individual Interests and Collective Action: Selected Essays Cambridge Univ. Press, Cambridge, pp. 1986

Colman AM, Pulford BD (2015) Psychology of game playing: Introduction to a special issue. Games 6(4):677-684

Croson R, Miller M (2004) Explaining the relationship between action and beliefs: Projection vs. reaction. Technical report, mimeo, New York

De Bruin WB, Fischhoff B (2017) Eliciting probabilistic expectations: Collaborations between psychologists and economists. Proc Natl Acad Sci, 114 (13):3297-3304

Dreber A, Rand DG, Fudenberg D, Nowak MA (2008) Winners don't punish. Nature 452(7185):348-351

Elster J (1989) The cement of society: A survey of social order. Cambridge University Press, New York

Eshaghi Gordji M, Askari G (2018) Hyper-rational choice and economic behavior. Adv Math Financ Appl 3(3):69-76

Eshaghi Gordji M, Askari G, Park C (2018) A new behavioral model of rational choice in social dilemma game. J Neurodev Cogn 1(1):40-49

Eshaghi Gordji M, Askari G (2017) Dynamic system of strategic games. Int. J. Nonlinear Anal Appl 9(1):83-98

Fehr E, Gachter S (2002) Altruistic punishment in humans. Nature 415 (6868):137-140

Gallo E, Yan C (2015) The effects of reputational and social knowledge on cooperation. Proc Natl Acad Sci 112(12):3647-3652

Geanakoplos J, Pearce D, Stacchetti E (1989) Psychological games and sequential rationality. Games Econ Behav 1(1):60-79

Hamilton WD, Axelrod R (1981) The evolution of cooperation. Science 211 (27):1390-1396

Hardin R (1995) One for all: The logic of group conflict. Princeton Univ. Press, Princeton

Harsanyi JC (1986) Rational behaviour and bargaining equilibrium in games and social situations. Cambridge University Press, Cambridge

Harsanyi JC (1980) Advances in understanding rational behavior. In Rational Choice, Elster J (ed), New York University Press, New York

Hertel G, Fiedler K (1994) Affective and cognitive influences in social dilemma game. Eur J Soc Psychol 24(1):131-145. 1994

Hofstadter D (2008) Metamagical themas: Questing for the essence of mind and pattern. Basic books, New York

Huang K, Liu Y, Zhang Y, Yang C, Wang Z (2018) Understanding cooperative behavior of agents with heterogeneous perceptions in dynamic networks. Phys A: Stat Mech its Appl 509:234-240

Huang K, Zhang Y, Li Y, Yang C, Wang Z (2018) Effects of external forcing on evolutionary games in complex networks. Chaos: An interdisciplinary. J Nonlinear Sci 28(9):093108 
Jordan J, Hoffman M, Bloom P, Rand DG (2016) Third-party punishment as a costly signal of trustworthiness. Nature 530(7591):473-476

Kuran T (1995) Private Truths, Public Lies. The Social Consequences of Preference Falsification. Harvard Univ. Press, Cambridge

Li HJ, Bu Z, Li A, Liu Z, Shi Y (2016) Fast and accurate mining the community structure: integrating center locating and membership optimization. IEEE Trans Knowl Data Eng 28(9):2349-2362

Li HJ, Bu Z, Li Y, Zhang Z, Chu Y, Li G, Cao J (2018) Evolving the attribute flow for dynamical clustering in signed networks. Chaos, Solitons Fractals 110:20-27

Li HJ, Daniels JJ (2015) Social significance of community structure: Statistical view. Phys Rev E 91(1):012801

Li X, Jusup M, Wang Z, Li H, Shi L, Podobnik B, Stanley HE, Havlin S, Boccaletti S (2018) Punishment diminishes the benefits of network reciprocity in social dilemma experiments. Proc Natl Acad Sci 115(1):30-35

Loomes G, Sugden R (1982) Regret theory: An alternative theory of rational choice under uncertainty. Econ J 92(368):805-824

Manski CF (2017) Collaboration, conflict, and disconnect between psychologists and economists. Proc Natl Acad Sci 114(13) 3286-3288

Mathew S, Boyd R (2011) Punishment sustains large-scale cooperation in prestate warfare. Proceedings of the National Academy of Sciences, 108 (28):11375-11380

McCarty N, Meirowitz A (2007) Political game theory: an introduction. Cambridge University Press, New York

Moorthy KS (1985) Using game theory to model competition. J Mark Res 22 (3):262-282

Nash JF (1950) Equilibrium points in n-person games. Proc Natl Acad Sci 36 (1):48-49

Nash JF (1951) Non-cooperative games. Ann Math 54:286-295

Nowak MA (2006) Five rules for the evolution of cooperation. science 314 (5805):1560-1563

Oberschall A (1973) Social Conflict and Social Movements.. Prentice-Hall, Englewood Cliffs

Oberschall A (1994) Regles, normes, morale: emergence et sanction. L’Annee Socio 44:357-84

Ohtsuki H, Iwasa Y, Nowak MA (2009) Indirect reciprocity provides only a narrow margin of efficiency for costly punishment. Nature 457(7225):79-82

Olson M (1965) Logic of collective action: Public goods and the theory of groups (Harvard economic studies. v. 124). Harvard University Press, Cambridge, Massachusetts

Osang T, Nandy A (2013) Environmental regulation of polluting firms: Porter's hypothesis revisited. Revista Brasileira de Economia de Empresas 3 (3):128-148

Osborne MJ (2004) An introduction to game theory, volume 3. Oxford university press, New York, NY

Poston T (2012) Social evil. Oxf Stud Philos Relig 5:166-185

Poundstone W (1993) Prisoner's Dilemma/John von Neumann, game theory and the puzzle of the bomb. Anchor Books, New York

Rand DG, Arbesman S, Christakis NA (2011) Dynamic social networks promote cooperation in experiments with humans. Proc Natl Acad Sci, 108 (48):19193-19198

Rand DG, Dreber A, Ellingsen T, Fudenberg D, Nowak MA (2009) Positive interactions promote public cooperation. Science 325(5945):1272-1275

Rand DG, Greene JD, Nowak MA (2012) Spontaneous giving and calculated greed. Nature 489(7416):427-430

Rand DG, Nowak MA, Fowler JH, Christakis NA (2014) Static network structure can stabilize human cooperation. Proc Natl Acad Sci, 111 (48):17093-17098

Rockenbach B, Milinski M (2006) The efficient interaction of indirect reciprocity and costly punishment. Nature 444(7120):718-723
Root HL (1994) The fountain of privilege: Political foundations of economic markets in old regime France and England. Univ. Calif. Press, Berkeley

Rothstein B (2001) The universal welfare state as a social dilemma. Ration Soc 13 (2):213-33

Sigmund S, Hauert C, Nowak MA (2008) Reward and punishment. Proc Natl Acad Sci, 98(19):10757-10762

Simon HA (1955) A behavioral model of rational choice. Q J Econ 69(1):99-118 Simon HA (1972) Theories of bounded rationality. Decis Organ 1(1):161-176

Schlaifer R, Raiffa H (1961) Applied statistical decision theory. Clinton Press Inc., Boston, MA, USA

Schotter A, Trevin I (2014) Belief elicitation in the laboratory. Annu Rev Econ 6 (1):103-128

Traulsen A, Nowak MA (2006) Evolution of cooperation by multilevel selection. Proc Natl Acad Sci 103(29):10952-10955

Trivers RL (1971) The evolution of reciprocal altruism. Q Rev Biol 46(1):35-57

Tversky A, Kahneman D (1986) Rational choice and the framing of decisions. Journal of Business 59: 251-278

Udehn L (2002) Methodological individualism: Background, history and meaning. Routledge, London

Von Neumann J, Morgenstern O (1953) Theory of game and economic behavior. Princeton University Press, Princeton, New Jersey

Webb JN (2007) Game theory: decisions, interaction and Evolution. Springer Science and Business Media, London

Weber M (1978) Economy and society: An outline of interpretive sociology. Univ of California Press, Berkeley

Xia C, Li X, Wang Z, Perc M (2018) Doubly effects of information sharing on interdependent network reciprocity. New J Phys 20(7):075005

Xia C, Wang Z, Zheng C, Guo Q, Shi Y, Dehmer M, Chen Z (2019) A new coupled disease-awareness spreading model with mass media on multiplex networks. Inf Sci 471:185-200

\section{Acknowledgements}

This research is supported by Iran National Science Foundation (No. 96002125).

\section{Additional information}

Competing interests: The authors declare no competing interests.

Reprints and permission information is available online at http://www.nature.com/ reprints

Publisher's note: Springer Nature remains neutral with regard to jurisdictional claims in published maps and institutional affiliations.

(c) (i) Open Access This article is licensed under a Creative Commons Attribution 4.0 International License, which permits use, sharing, adaptation, distribution and reproduction in any medium or format, as long as you give appropriate credit to the original author(s) and the source, provide a link to the Creative Commons license, and indicate if changes were made. The images or other third party material in this article are included in the article's Creative Commons license, unless indicated otherwise in a credit line to the material. If material is not included in the article's Creative Commons license and your intended use is not permitted by statutory regulation or exceeds the permitted use, you will need to obtain permission directly from the copyright holder. To view a copy of this license, visit http://creativecommons.org/ licenses/by/4.0/.

(C) The Author(s) 2019 